MORE LIGHT ON ANCIENT BRITAIN. ${ }^{1}$

$\mathrm{T} \mathrm{T}$ is gratifying, and at the same time puzzling, to find that the antiquities discovered in part of a single county can provide material for two such voluminous works as Canon Greenwell's "British Barrows" of I877 and the record of Mr. Mortimer's researches, now issued with the assistance of $\mathrm{Mr}$. Sheppard, the energetic curator of the Hull Municipal Museum. The district investigated lies between York and Bridlington, and teems with relics of the past, most of the barrows, or burial mounds, dating from the Bronze Age, but two or three cemeteries containing Anglo-Saxon graves at least a thousand years later. The excavations in which the author has been concerned for so many years are well described; but those without special knowledge of the period will turn with most satisfaction to the introduction, where, with the aid of copious extracts from the earlier work already mentioned, some interesting generalisations are made from the data furnished by the spade. Evidence is brought forward in favour of cannibalism among the ancient Britons, a practice that has been suspected for some time; and human sacrifice, perhaps also suttee, seems to have been indulged in at the burial of an important personage. In some barrows there were signs that a circular hut or a pit-dwelling had been used as a sepulchre, the walls and roof being thrown down over the body; and the author's suggestion as to the

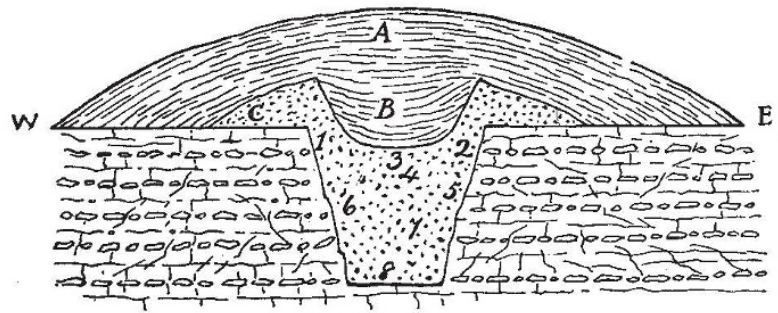

FIG. I.-Section of Round Barrow, Aldro, E.R. Yorks.

origin of the incomplete ring formed by stones or a trench round many burials of the period is certainly plausible. In his own words, "these rings are probably marks of taboo or enclosures which were made at the beginning of the ceremony to mark off and protect the sacred spot in which the ceremony and interment were afterwards to be conducted, and the break in the circle had no other significance than to serve as a place of ingress and egress during the performance of the obsequies."

It is interesting to have existing evidence as to the sepulchral pottery confirmed by further discoveries. With a few very doubtful exceptions the so-called "drinking-cup" is never found with calcined human bones, and generally accompanies the primary, or at least one of the earliest burials, in the mound or the grave beneath it. Of the "foodvessels," 43 were found with cremations and II with unburnt skeletons; and these figures agree with Canon Greenwell's, giving a proportion of about one to three. Though occasionally found on the top of calcined bones, the cinerary urns, as their name implies, were generally used to contain the ashes of the dead, and "incense-cups" are invariably associated with the rite of cremation, though we must contest the statement that the latter vessels are also

1 “'Forty Years' Researches in British and Saxon Burial Mounds of East Yorkshire." By J. R. Mortimer. Illustrated by Agnes Mortimer. Pp. ixxxvi+452. (Hull : A. Brown and Sons, Ltd., r9o5.) found in Scandinavia, Germany, France, and even the Troad.

The intricacies of the text are considerably simplified by numerous diagrams, giving the plan and vertical section of the barrow under examination, and a specimen is here reproduced to show how it is possible to read the history of a burial mound. One in the Aldro group measuring 84 feet in diameter and 5 feet in height was excavated in 1866 . The clay and soil forming the upper part is marked $A$, while $B$ is a boat-shaped mass of clay and soil below it, $\mathrm{c}$ being the chalk filling of the inner mound and grave below the original surface-level Ew. Nos. I-8 are interments of children and adults in a pit cut rather deeper than usual in the chalk rock; but they were not all complete skeletons, No. 7 , for instance, being a heap containing a "drinking-cup " in 48 pieces, fragments of six human lowerjaws, and a number of small bones packed in an adult calvarium. Whether con temporary or not, these burials had been surmounted by a dome of chalk which was cut into for another burial at some later date and subsequently covered with the outer mound.

Of the succeeding. Early Age of iron remains are few in this particular district, though abundant a few miles further north; but one burial of importance must be noted. The swords here illustrated were found with a skeleton, and belong to two distinct types; the longer is of usual dimensions and has the characteristic curved scabbard-mouth and the chape of the middle period of La Tène, while the shorter sword is the only one of the kind known to have been found in this country, and with similar examples from France and Switzerland may date from about roo B.c. The human head between the branches of the pommel is evolved from the knob that appears in that position on certain short swords from the Hallstatt cemetery.

The Anglo-Saxon cemeteries contain unburnt

bodies of which the orientation is instructive, while many excellent brooches and other relics have been recovered. These and the vast Bronze Age series have been amply and creditably illustrated, but, ungallant as it may appear, a protest must be lodged against the frontispiece, which gives a totally false impression of the Grimthorpe sword. In a work containing so many references misprints are excusable, but some are irritating; thus, Inverary (p. 36I) NO. I869, VOL. 72] 
should be Inverury, and the next page has a cruel mutilation of Le Gros Guignon, while the reference to Archaeological Journal on the page before should be to the York volume ( 1848 ).

Following an excellent example, Mr. Mortimer furnishes relic-tables with all necessary details at the end of the volume, together with a copious index. Comparison with Canon Greenwell's table shows a very large proportion of primary interments, there being in one case as many as seventeen, to three secondary; but in a matter of this kind different conclusions might be drawn from the same data. Altogether the work is most welcome as a fund of material for more general treatment, and should encourage the study and publication of prehistoric finds in England.

\section{THE FORTHCOMING TOTAL SOLAR} ECLIPSE.

$\mathrm{B}^{\mathrm{Y}}$ the time that Nature appears next week, the total solar eclipse of August 30 will have become an event of the past, and we hope then to be in a position to announce that the careful preparations, which have occupied the minds of astronomers for so many months past, have been crowned with success.

Since the appearance of Dr. Lockyer's article concerning the eclipse, in our issue of February 23, several important modifications in the proposed arrangements have been made, but most of the eclipse observers are now at their stations erecting or adjusting their instruments for the final scene on Wednesday next. How much depends on the nicety of these adjustments can only be understood by those intimately concerned; but when it is recalled that since the general introduction of photographic methods into eclipse work the sun has only been eclipsed for about half an hour, that the duration of totality in the coming event exceeds $3 \frac{3}{4}$ minutes, and that no favourable opportunity. will occur again until I9I2, when totality will only last for about 60 seconds, some idea may be obtained of the anxiety of those observers who are fortunate enough to take an active part in next Wednesday's observations.

Subjoined to this article is a letter from Dr. W. J. S. Lockyer describing the preliminary operations of the eclipse expedition of the Solar Physics Observatory, under the personal direction of Sir Norman Lockyer, K.C.B. When all arrangements for this expedition were nearly completed, but before Sir Norman Lockyer left England, it was decided by the French Government, in quite a friendly spirit, that the presence of a foreign man-of-war in Philippeville harbour was not desirable at the present time; therefore arrangements were made with the Spanish authorities, who rendered such valuable help to the similar expedition in 1900 , for the party to go to Palma. Some of the work contemplated at Palma is described by Dr. Lockyer in his letter.

Some novel observations will be made by other observers. In a recent communication to the British Astronomical Association Mr. C. E. Stromeyer pointed out that geodesy might be assisted by an accurate determination of the path of totality. This path has been computed on the assumption that the earth has a certain form, and if the computed values are found to be incorrect, the errors in the assumption might be discovered. Another valuable suggestion was made in a letter from Dr. Johnstone Stoney which appeared in these columns on July $\mathrm{I}_{3}$, wherein the writer pointed out that the planet Mercury will be very near to a line joining the earth and the sun, and will therefore present a very thin crescent to the observer's view. No. I 869 , vOL. 72]
If Mercury has an atmosphere, the horns of the crescent should appear prolonged by atmospheric refraction, and a careful observer, suitably equipped, should be able to detect the prolongation, and possibly to observe the spectrum of the tips.

M. Touchet suggests that the moon might be observed, both before the first and after the fourth contacts, projected on the brighter portions of the lower corona, by an observer employing a suitable dark glass with a small telescope.

In a brochure recently received from Señor Horacio Bentabol, of Madrid, the author makes a number of suggestions to eclipse observers by which the existence of a lunar atmosphere might be detected. Among other matters he suggests that delicate thermometric observations made for some hours before and after the eclipse might exhibit a heat-absorption effect due to the interposition of the lunar atmosphere, between the sun and the observer, before the actual body of the moon was interposed. Solar radiation observations might also exhibit the same effect. Photometric observations of the illumination of the sky might show an analogous absorption of light, due to the lunar atmosphere. Exact determinations of the solar diameter would, if the moon possesses an atmosphere, probably show the results of the refraction due to that atmosphere. The apparent hourly movement of the sun should become modified, as the lunar atmosphere is interposed, for the same reason. Many other points whereby the existence of such an atmosphere might be tested are given by Señor Bentabol.

As recently mentioned in these columns, French astronomy will be well represented at the various stations, whilst American astronomers have journeyed to a number of widely separated stations. Three expeditions have been sent from the Lick Observatory to Labrador, Spain, and Egypt respectively. At each station a search is to be made for an intraMercurial planet, and large-scale coronagraphs of exactly similar construction are to be employed. Should any actual movements take place in the corona during the two and a half hours which elapse between totality at Labrador and at Assouan, the photographs obtained at these respective stations should show it.

The Canadian Government has dispatched an expedition to Labrador, and has officially invited Mr. and Mrs. E. W. Maunder to accompany the same. Mrs. Maunder will employ a coronagraph exactly similar to that which Prof. Turner is using in Egypt.

The details concerning the regions crossed by the eclipse track, and the times of totality, \&c., have already been given in many places, but the subjoined table griving the times and magnitude of the greatest phase in these islands may be of interest :-

\begin{tabular}{|c|c|c|c|c|c|}
\hline & $\begin{array}{l}\text { Eclipse begins } \\
\text { d. h. m. }\end{array}$ & $\begin{array}{l}\text { Greatest eclips } \\
\text { d. h. m. }\end{array}$ & & $\begin{array}{l}\text { Eclipse ends } \\
\text { d. h. m. }\end{array}$ & \\
\hline & 292349 & $\cdots \quad 30$ I 4 & $\cdots$ & 30215 & $\cdots$ \\
\hline E & $2923 \quad 44$ & $30 \circ 55$ & $\ldots$ & 3024 & $\ldots$ \\
\hline & $\begin{array}{lll}29 & 23 & 39\end{array}$ & $30 \circ 53$ & $\ldots$ & 302 & $\ldots$ \\
\hline
\end{tabular}

In the above table, which is taken from the Com panion to the Observatory, the times are Greenwich Mean Time, which is reckoned from the previous mean noon, and the magnitude is given with the sun's whole diameter as unity.

\section{The Solar Physics Observatory Eclipse Expedition.}

Palma, August I8.

We have now been at Palma a week to-day, and are all thoroughly settled down, not only at the very excellent hotel in which we are located, but at the eclipse camp, which lies about a mile towards the north-west. We are a large party. There are 